Copyright Philosophy of Science 2017

Preprint (not copyedited or formatted)

Please use DOI when citing or quoting

\title{
Newton: from certainty to probability?
}

\begin{abstract}
Newton's earliest publications contained scandalous epistemological claims: not only did he aim for certainty, but claimed success! Some commentators argue that Newton ultimately gave up claims of certainty in favour of a high degree of probability. I argue that no such shift occurred. I examine the evidence of a probabilistic shift: a passage from query 23/31 of the Opticks and rule 4 of the Principia. Neither passage supports a probabilistic approach to natural philosophy. The aim of certainty, then, was an enduring feature of Newton's methodology.
\end{abstract}

\author{
Author details \\ Kirsten Walsh \\ Philosophy Department, University of Nottingham \\ walsh.kirsten@gmail.com
}

\section{Acknowledgements}

For valuable comments on previous versions of this paper I would like to thank Adrian Currie, Niccolò Guicciardini, Craig Fox and Alan Shapiro. The paper also benefited from helpful discussions at the 2015 workshop on 'Natural History, Mathematics, and Metaphysics in the Seventeenth Century' at the Institute for Research in the Humanities, University of Bucharest. 
Copyright Philosophy of Science 2017

Preprint (not copyedited or formatted)

Please use DOI when citing or quoting

\section{Introduction}

Newton's first optical paper (February 1672) contained a scandalous epistemological statement: not only did he aim for certain theories, but claimed success! Some of Newton's modern commentators claim that Newton eventually relinquished his claims of certainty, admitting only a high degree of probability. This view has been perpetuated by Alan Shapiro (e.g. Shapiro 1989, 225, 1993, 14) and, endorsed more recently, by Niccolò Guicciardini (Guicciardini 2011, 20). Shapiro views Newton's probabilist shift as gradual and somewhat private. He argues that the first shift occurred less than six months after writing that first optical paper-on the basis of the criticisms (Shapiro 1989, 228-29). However, he argues, Newton's first public statement of probabilism didn't occur until many years later. ${ }^{1}$ Shapiro writes, "Only in the last decades of his life did [Newton] accept the probabilism of his contemporaries" (Shapiro 1993, 14). ${ }^{2}$

Gradual though it may have been, this is a significant shift in Newton's thought. Newton's notion of certainty permeates his views, not only on the aim of science, but also the nature of evidence, the nature of scientific reasoning, and how he saw his achievements in mathematics and natural philosophy (e.g. Walsh 2011). Shapiro has identified two key pieces of textual evidence for this shift: the first, a response to Hooke in June 1672; and the second, an explicit statement of probabilism in query 23/31 of the Opticks (introduced in 1717). ${ }^{3}$

I argue that Newton remained committed to certainty. Firstly, I examine the relevant passage from query 23/31 of the Opticks and a related passage, rule 4, from the Principia. I argue that neither of these passages should be interpreted as supporting probabilism. Secondly, I examine the relevant passage from Newton's correspondence with Hooke in 1672. I argue that this passage expresses a similar qualified notion of certainty as that which Newton had expressed two years earlier, in his Optical Lectures in 1670. Finally, I characterise Newton's notion of certainty as 'compelled assent', and conclude that this was an enduring feature of Newton's methodology.

\section{1717: Newton's First Public Statement of Probabilism?}

That Newton claimed some kind of certainty in his early work (in his first optical paper, for instance) is uncontroversial. Exactly what this 'certainty' amounted to is less clear. I offer an account of this in the final section. For now, let's put this issue to one side and focus on Newton's apparent shift to probabilism. In this section, I'll assess Shapiro's claim that a passage from query $23 / 31$ should be interpreted as probabilism. First, I introduce the relevant passage

${ }^{1}$ Alan Shapiro, private correspondence.

${ }^{2}$ See also (Shapiro 1989, 225).

${ }^{3}$ It is interesting to note that Guicciardini endorses the first shift, but not the second (c.f. Guicciardini 2011, 20 \& 14). 
Copyright Philosophy of Science 2017

Preprint (not copyedited or formatted)

Please use DOI when citing or quoting

from query 23/31 and a related passage from the Principia-rule 4-clarifying the standard (probabilistic) interpretation of these passages. I then offer an alternative interpretation, based on the application of rule 4 to Newton's argument for universal gravitation: rule 4 advises us to adjust the scope of generalisations, not our credence. Applying this thinking to the original passage, I conclude that this isn't a statement of probabilism and so doesn't represent a shift in Newton's thinking about certainty.

\subsection{The Probabilist Interpretation of Query 23/31 and Rule 4}

In 1717, Newton published the second edition of the Opticks, in which he re-labelled query 23 as 'query $31,{ }^{4}$ and expanded the methodological discussion. Here, Newton described his methods of analysis and synthesis (or composition). Newton's method of analysis involved drawing general propositions from observations and experiments, and more generally, inferring causes from effects. The method of composition is the inverse: we assume the causes and infer their effects. The ordering of these methods was important: the method of composition should always follow the method of analysis, using the causes discovered by analysis to explain their effects, thus "explaining the Phænomena" and "proving the Explanations" (Newton 1952, 405). ${ }^{5}$

Expanding on his method of analysis, Newton wrote the following (which I'll refer to as 'P'):

If no Exception occur from Phænomena, the Conclusion may be pronounced generally. But if at any time afterwards any Exception shall occur from Experiments, it may then begin to be pronounced with such Exceptions as occur (Newton 1952, 404).

We might be forgiven for interpreting $\mathrm{P}$ in hypothetico-deductive terms, as it seems to suggest that the epistemic status of a theory ought to be sensitive to new evidence. Indeed, according to Shapiro, this is Newton's first public probabilistic statement.

This is a mistake.

To understand why, we should see how Newton applied P in practice. Although P was not invoked explicitly in the Opticks, the same notion can be found in another late addition to Newton's work, rule 4 of the Principia. ${ }^{6}$

${ }^{4}$ I follow convention in referring to this as 'query $23 / 31$ '.

${ }^{5}$ In this passage, Newton interchangeably referred to the methods of composition and synthesis. For discussion, see (Ducheyne 2012, 6-8 \& 18-25) and (Guicciardini 2011, 74-78).

${ }^{6}$ While the Opticks and the Principia ostensibly deal with different subject matter, query 23/31 goes beyond optics, to discuss various forces, motions and systems, including universal 
Copyright Philosophy of Science 2017

Preprint (not copyedited or formatted)

Please use DOI when citing or quoting

In the third edition of the Principia (1726), Newton added a fourth 'rule for philosophising': ${ }^{7}$

Rule 4. In experimental philosophy, propositions gathered from phenomena by induction should be considered either exactly or very nearly true notwithstanding any contrary hypotheses, until yet other phenomena make such propositions either more exact or liable to exceptions.

This rule should be followed so that arguments based on induction may not be nullified by hypotheses (Newton 1999, 796).

The similarities between this rule and $\mathrm{P}$ are striking: that new evidence can make a proposition "either more exact or more liable to exceptions" is similar to pronouncing the conclusion either "more generally" or "with such Exceptions as occur".

Rule 4 looks like a pragmatic response to the problem of induction: Newton's recognition that uncertainty was introduced by ampliative inference, i.e. generalising from particulars. ${ }^{8}$ The phrase "very nearly true" could mean 'highly probable'. So, it might seem reasonable to put the following hypothetico-deductive gloss on rule 4 :

If our best theory fits all the known facts, then we should act as though it is highly probable (i.e. tentatively accept it) until more facts either support or refute it.

I take it that an interpretation of this kind is the source of Shapiro's claim. ${ }^{9}$ However, I argue that this is a misinterpretation of rule 4. Rule 4 was employed explicitly in the Principia-in the argument for universal gravitation. This use should tell us how to interpret the rule itself and, by extension, $\mathrm{P}$.

gravitation. Moreover, query 23/31 discusses the other rules for philosophising-explicitly drawing methodological connections between the Principia and the Opticks. So I believe I am justified in drawing this comparison.

${ }^{7}$ The rules act as explanatory constraints, or heuristics, enabling Newton to make inferences from phenomena and theorems to further theorems.

${ }^{8}$ For an account of Newton's method of 'inductive gradualism', see (Ducheyne 2005).

${ }^{9}$ Indeed, Shapiro's hypothetico-deductive reading of the development of Newton's theory of fits (Shapiro 1993, 200) suggests that he supports the hypothetico-deductive interpretation of Newton's method more generally. 
Copyright Philosophy of Science 2017

Preprint (not copyedited or formatted)

Please use DOI when citing or quoting

\subsection{Rule 4 and Newton's Argument for Universal Gravitation}

In the Principia, Newton only explicitly employed rule 4 once, in his argument for universal gravitation, proposition 5 book 3 :

Proposition 5. The circumjovial planets gravitate toward Jupiter, the circumsaturnian planets gravitate toward Saturn, and the circumsolar planets gravitate toward the sun, and by the force of their gravity they are always drawn back from rectilinear motions and kept in curvilinear orbits (Newton 1999, 805).

The argument takes the following form:

$\mathrm{P} 1$. In system $\mathrm{S}_{1}$, effect $\mathrm{E}$ is caused by $\mathrm{G}$.

P2. The same effect $E$ also occurs in systems $S_{2}, S_{3}, \ldots, S_{n}$.

P3. Whenever the same effect occurs, we should infer the same cause.

P4. $\quad G$ is sufficient to cause $E$ in systems $S_{2}, S_{3}, \ldots, S_{n}$.

P5. If $G$ is sufficient to cause effect $E$ in systems $S_{2}, S_{3}, \ldots, S_{n}$, then we should infer $\mathrm{G}$, and no other causes of $\mathrm{E}$.

C. In systems $S_{2}, S_{3}, \ldots, S_{n}$, effect $E$ is caused by $G$, and no other causes (from P1, P2, P3, P4 \& P5).

Newton's argument for universal gravitation proceeds step-by-step from the motion of the moon with respect to the Earth, the motions of the moons of Jupiter and Saturn with respect to Jupiter and Saturn and the motions of the planets with respect to the Sun, to the forces producing those motions. Thus, in this argument, system $\mathrm{S}_{1}$ refers to the two-body Earth-Moon system. Systems $\mathrm{S}_{2}, \mathrm{~S}_{3}, \ldots, \mathrm{S}_{\mathrm{n}}$ refer respectively to two-body systems involving Jupiter and each of its moons, Saturn and each of its moons, and the Sun and each of the planets.

In the scholium following proposition 5, Newton said:

Hitherto we have called 'centripetal' that force by which celestial bodies are kept in their orbits. It is now established that this force is gravity, and therefore we shall call it gravity from now on. For the cause of the centripetal force by which the moon is kept in its orbit ought to be extended to all the planets, by rules 1, 2, and 4 (Newton 1999, 806).

Rules 1 and 2 tell us not to postulate more causes than are sufficient for the effect (P5), and that we should assume that effects of the same kind have causes of the same kind (P3). Rule 4 tells us that (a) we ought to regard proposition 5 as "either exactly or very nearly true", (b) new observational evidence may make proposition 5 "either more exact or liable to exceptions", and (c) proposition 5 may not be refuted by "contrary hypotheses". I noted above that rule 4 seems 
Copyright Philosophy of Science 2017

Preprint (not copyedited or formatted)

Please use DOI when citing or quoting

to invite us to regard propositions as highly probable until other evidence either increases or decreases our credence in the proposition.

I now suggest an alternative reading of this rule, addressing the three parts of rule 4 in turn.

\section{a) We ought to regard proposition 5 as "either exactly or very nearly true".}

This tells us what epistemic attitude we should take to propositions. The phrase "either exactly or very nearly true" is usually interpreted as 'highly probable'. However, I now argue for an alternative reading of this passage. In the original Latin, the relevant phrase in rule 4 appears as "[...] pro veris aut accurate aut quamproxime haberi debent [...]" (Newton 1972, 555). In Latin, quamproxime literally means 'closest (proxime) in the highest possible degree (quam)'. In their translation of the Principia (Newton 1999), Cohen and Whitman translate the phrase as 'very nearly'. Indeed, out of context, this seems to be a reasonable translation. However, many commentators agree that this does not capture the strength and significance of the phrase when used by Newton. For example, Ducheyne has made a strong case for the translation "as most closely as possible" (Ducheyne 2013, 82-92), whereas George Smith prefers to treat 'quamproxime' as a technical term (e.g. Smith 2002). ${ }^{10}$

So what does quamproxime mean in this context? Newton approached universal gravitation via a series of increasingly complex model systems. In book 1 of the Principia, he modelled the laws of motion in a one-body system, establishing that a body would display perfect Keplerian motion when acted on by an inverse square centripetal force. This is because, in a one-body system, there is no mutual attraction. But, once he added a second body, he found that, if a body displays Keplerian motion quamproxime, then it is maintained by a centripetal force directed quamproxime towards a central body (Newton 1999, 448). That is, the consequent holds quamproxime as long as the antecedent holds quamproxime. 'Quamproxime' captures the degree to which orbits are perturbed by other bodies in the system.

In short, this phrase tells us that we should take this proposition as true, which is to say it captures the essential dynamics of the system.

\section{b) New observational evidence may make proposition 5 "either more exact or liable to exceptions".}

This tells us what to do in the face of new evidence. The probabilist reading says that new evidence either increases or decreases our credence in the proposition. I prefer a different interpretation: if exceptions to proposition 5 occur, instead of reducing our credence in the proposition, we should add detail (thus, making it more accurate), or de-generalise the

${ }^{10}$ On the role of 'quamproxime propositions' in the Principia, see (Ducheyne 2013, 82-92) and (Smith 2002, 155-56). 
Copyright Philosophy of Science 2017

Preprint (not copyedited or formatted)

Please use DOI when citing or quoting

proposition (thus, restricting the domain to which it applies). De-generalising a proposition does not reduce certainty; rather, it reduces the proposition's scope while maintaining certainty.

Newton expressed this idea much more clearly in draft material:

If a proposition gathered by induction is not sufficiently accurate, then it should be corrected, not by introducing (ad hoc) hypotheses, but by more widely and accurately observed phenomena of nature. If this turns out impossible, however, then the proposition should be de-generalized (Ducheyne 2012, 119). ${ }^{11}$

Thus, if faced with 'contrary instances', we should reduce the domain to which the proposition applies: it is true, but true of fewer instances.

\section{c) Proposition 5 may not be refuted by "contrary hypotheses".}

This claim instructs us in the treatment of 'contrary hypotheses'. A theory's uncertainty could be sourced in countervailing evidence or competing theories. (c) is often interpreted as denying that competing theories can change our credence in the present theory. Take Peter Achinstein's reading, for example:

There may be another hypothesis, incompatible with yours, from which the same phenomena can be derived and explained. If so, then, according to the hypotheticodeductivist, that hypothesis would also be established. But two incompatible hypotheses can't both be established on the basis of the same phenomena. From the 'mere possibility' of a hypothesis - that is, from the mere fact that it entails and explains a range of phenomena-you cannot conclude that it is true (Achinstein 2013, 74-75).

Similarly, Bill Harper takes contrary hypotheses as alternative propositions that are not "sufficiently supported empirically to be counted as serious rivals" (Harper 2011, 109). Such interpretations, we shall see, miss the point. Newton tells us that hypotheses must not influence our epistemic attitude towards the theory (i.e. proposition 5). That is, according to rule 4, only phenomena (i.e. observed motions of celestial bodies) can influence the universality of proposition 5.

My interpretation of this claim turns on Newton's (unique) distinction between 'theories' and 'hypotheses'. Although well-established among Newton scholars, the distinction is not well-understood, so it is worth covering here.

${ }^{11}$ Ducheyne's translation and paraphrasing of draft material relating to the Principia, $2^{\text {nd }}$ edition. 
Copyright Philosophy of Science 2017

Preprint (not copyedited or formatted)

Please use DOI when citing or quoting

In Newton's methodology, theories and hypotheses deal with different subject matter, have different epistemic statuses, and perform different roles. Theories systematise the observable, measurable properties of things; hypotheses describe the (unobservable) nature of things. Theories are inferred from observation and experiment; hypotheses are speculative. For example, Newton saw universal gravitation as a theory, since it was inferred from celestial and terrestrial observations, and systematised those observations. However, an explanation of the nature and cause of gravity would be a hypothesis, since it concerns the unobservable, and is speculative, rather than inferred from experiment. The distinction is nicely captured in a draft letter from Newton to Roger Cotes (March 1713):

One may suppose that bodies may by an unknown power be perpetually accelerated and so reject the first law of motion. One may suppose that God can create a penetrable body and so reject the impenetrability of matter. But to admit of such hypotheses in opposition to rational propositions founded upon phenomena by induction is to destroy all arguments taken from phenomena by induction and all principles founded upon such arguments (Newton 2004, 120).

Recall that rule 4 tells us that hypotheses may not refute or alter "arguments gathered from phenomena", namely, theories. For Newton, theories were on epistemically surer footing than hypotheses because they were grounded in phenomena, whereas hypotheses were grounded in speculation. When faced with disagreement between hypotheses and theories, we should modify the hypothesis to fit the theory, not vice versa. Newton explained this idea in the same letter to Cotes:

And therefore as I regard not hypotheses in explaining the phenomena of nature, so I regard them not in opposition to arguments founded upon phenomena by induction or to principles settled upon such arguments. In arguing for any principle or proposition from phenomena by induction, hypotheses are not to be considered. The argument holds good till some phenomenon can be produced against it (Newton 2004, 120). ${ }^{12}$

So, according to rule 4:

1. In the absence of exceptions, we should take gravity to be universal;

2. If exceptions to universal gravitation are found, we should infer that the domain of the theory of gravitation is limited (i.e. not universal); and

12 This is the idea Newton expressed with his (in)famous phrase 'hypotheses non fingo' (Newton 1972, 584). 
Copyright Philosophy of Science 2017

Preprint (not copyedited or formatted)

Please use DOI when citing or quoting

3. We should not allow our imagined possibilities (e.g. the possibility of a penetrable body), or assumptions about natural mechanisms (e.g. the implausibility of action at a distance), to have any influence on our epistemic attitude towards universal gravitation.

Rule 4, then, should not be read probabilistically. Newton uses it to claim that the theory of universal gravitation is certain, that exceptions should lead us to restrict the domain of the theory, and that ideas about the nature of gravitation, that is, hypotheses about it, should play no epistemic role. Let's apply this kind of thinking to query $23 / 31$.

\subsection{Revisiting Query 23/31}

Recall P:

If no Exception occur from Phænomena, the Conclusion may be pronounced generally. But if at any time afterwards any Exception shall occur from Experiments, it may then begin to be pronounced with such Exceptions as occur (Newton 1952, 404).

This passage is similar to part of rule 4 of the Principia: new observational evidence may make a theory "either more exact or liable to exceptions" (Newton 1999, 796). From its application in the argument for universal gravitation (proposition 5), we have seen that rule 4 tells us, in the face of refutation, to update a theory's scope, not its epistemic warrant. Generalisations may be de-generalised, but de-generalisation does not reduce credence. That is, it doesn't take you from certainty to probability. P should be read in the same way. Newton doesn't suggest that we lower our credence in the face of countervailing evidence; rather, we should maintain certainty, but decrease scope.

\section{June 1672 and Newton's Early Optical Work}

In this section, I assess Shapiro's claim that Newton's response to Robert Hooke (June 1672) represents the first stage in a gradual shift in Newton's thinking about certainty. Firstly, I'll get clearer on Shapiro's claim by contrasting Newton's February 1672 statement with his response to Hooke in June 1672. We'll see that, in June 1672, Newton's claims about certainty are apparently more moderate than the statement from February 1672. This lends prima facie support to Shapiro's position. However, I'll challenge Shapiro's position with a methodological passage from Newton's Optical Lectures, completed in 1670. In this passage, Newton offers a moderate view, similar to the view he expressed in June 1672. This suggests that June 1672 does not mark a shift in Newton's thinking about certainty. Rather, Newton's notion of certainty was always somewhat moderate- but never probabilistic. I'll close by arguing that Newton's moderate 'certainty' is compelled assent.

\subsection{June 1672 and Newton's Response to Hooke}

Let's consider Newton's scandalous statement from February 1672: 
Copyright Philosophy of Science 2017

Preprint (not copyedited or formatted)

Please use DOI when citing or quoting

A naturalist would scearce expect to see ye science of [colours] become mathematicall, \& yet I dare affirm that there is as much certainty in it as in any other part of Opticks. For what I shall tell concerning them is not an hypothesis but most rigid consequence, not conjectured by barely inferring 'tis thus because not otherwise or because it satisfies all Phænomena (the Philosophers universall Topick,) but evinced by ye mediation of experiments concluding directly \& without any suspicion of doubt (Newton 1959-1977, Vol. 1, 96-97).

These are surprising ideas. While the Royal Society valued epistemic responsibility, ${ }^{13}$ Newton claimed certainty (apparently) without warrant. Indeed, the passage was omitted from the published version! ${ }^{14}$ Hooke was one of the few of Newton's contemporaries who read the passage; and it jarred. He objected that Newton was not justified in claiming that his theory was mathematically certain.

Newton responded that he had never claimed mathematical certainty:

I should take notice of a casuall expression wch intimates a greater certainty in these things then I ever promised, viz. The certainty of Mathematical Demonstrations (Newton 19591977, Vol. 1, 187).

He contrasted 'mathematical certainty' with the certainty offered by the 'mathematical sciences'. While the former is achieved by reasoning to mathematical theorems from mathematical principles; the latter starts with physical principles and reasons mathematically to physical propositions. Newton claimed to have achieved this latter certainty:

Now the evidence by wch I asserted the Propositions of colours is in the next words expressed to be from Experiments \& so but Physicall: Whence the Propositions themselves can be esteemed no more then Physicall Principles of a Science (Newton 1959-1977, Vol. 1, 187).

And from such physical principles, reasoning mathematically, Newton had derived a theory of colour. Therefore, his science of colours was "Mathematicall \& as certain as any part of Optiques" (Newton 1959-1977, Vol. 1, 188).

In this explanation, Newton suggests a more moderate certainty-pointing out that the certainty possible in optics is limited. He explained that the science of colours,

\footnotetext{
13 (e.g. Locke 1997/1690, Hooke 1966/1665, Preface).

${ }^{14}$ (c.f. Newton 1959-1977, Vol. 1, 96-97, 1672, 3077)
} 
Copyright Philosophy of Science 2017

Preprint (not copyedited or formatted)

Please use DOI when citing or quoting

Optiques \& many other Mathematicall Sciences depend as well on Physicall Principles as on Mathematicall Demonstrations: And the absolute certainty of a Science cannot exceed the certainty of its Principles (Newton 1959-1977, Vol. 1, 187).

So according to Newton, certainty in optics is limited by (at least) two things. Firstly, a proposition's certainty is constrained by the certainty of its principles. Secondly, optical principles are experimental, and hence, not mathematically certain. It is easy to see why Shapiro interprets this as a subtle shift towards probabilism. In February 1672 Newton emphasised the mathematism and certainty of his theory, but in June 1672, he emphasised the lack of mathematical certainty and the experimental basis of the theory. In the following section, however, I argue that no such shift occurred.

\subsection{Optical Lectures and Newton's Mathematico-Experimental Method}

Newton's approach was based on the idea that mathematics is a bearer of certainty-one can reason deductively from certain axioms to theorems, without losing certainty. Moreover, this method of reasoning is applicable to natural philosophy: one can reason deductively from laws and principles to propositions in natural philosophy, without epistemic loss. So, if one can establish certain natural philosophical laws or principles, it is possible to reason mathematically to certain propositions. Furthermore, Newton thought it was possible to establish a certain principle via a single experiment! ${ }^{15}$

Newton first indicated such a method in his Optical Lectures, which were completed by $1670 .{ }^{16} \mathrm{He}$ argued that natural philosophy should combine the insights of experimental philosophy and geometry - experimental techniques can rigorously investigate nature, while mathematical techniques enable reasoning to sound conclusions. In this way, we achieve an exact science ("accurata scientia" (Newton 1984, 86/438)) - a science that yields perfectly accurate knowledge of the world. The passage is worth quoting in extenso:

Thus although colours may belong to physics, the science of them must nevertheless be considered mathematical, insofar as they are treated by mathematical reasoning. Indeed, since an exact science of them seems to be one of the most difficult that philosophy is in need of, I hope to show - as it were, by my example - how valuable mathematics is in natural philosophy. I therefore urge geometers to investigate nature more rigorously, and those devoted to natural science to learn geometry first. Hence the former shall not

${ }^{15}$ In this mathematico-experimental methodology, Newton was almost certainly influenced by Isaac Barrow (e.g. Dunlop 2012, Guicciardini 2011, Shapiro 1993).

${ }^{16}$ Newton lodged two different versions with the Cambridge University Library. For transcriptions and translations, see (Newton 1984). 
Copyright Philosophy of Science 2017

Preprint (not copyedited or formatted)

Please use DOI when citing or quoting

entirely spend their time in speculations of no value to human life, nor shall the latter, while working assiduously with an absurd method, fail to reach their goal. But truly with the help of philosophical geometers and geometrical philosophers, instead of the conjectures and probabilities that are being blazoned about everywhere, we shall finally achieve a natural science supported by the greatest evidence (Newton 1984, 87-89/439).

In this passage, Newton contrasted the product of his mathematico-experimental method, "a natural science supported by the greatest evidence", with the "conjectures and probabilities" produced by less rigorous investigation and reasoning. Here, Newton explicitly presents his methodology in opposition to those who, "working assiduously with an absurd method", reach only probabilities rather than certainties. The passage shows us that what Newton had in mind, even in 1670, was a science of optics, grounded in experiment and observation, and mathematical only "insofar as [colours] are treated by mathematical reasoning". He didn't claim to have achieved mathematical certainty, but only the kind of certainty that could be achieved in natural philosophy from careful experiments and mathematical reasoning-just like in June 1672.

\section{Closing Remarks: Certainty as 'Compelled Assent'}

And so, Newton did not become a probabilist - he remained committed to the view that his methods produced certainty. But he did not mean mathematical certainty. What, then, is Newtonian certainty?

I close with a brief suggestion: ${ }^{17}$ Newton's certainty can be characterised as 'compelled assent'. ${ }^{18}$ When Newton claimed certainty, it was because he thought the evidence compelled him undeniably to his conclusion. For example, in his first paper (February 1672), Newton wrote:

And so the true cause [...] was detected to be no other then that Light consists of Rays differently refrangible [...] (Newton 1959-1977, Vol. 1, 95-underlining added).

And to Hooke (June 1672), he wrote:

And that this whitenesse is produced onely by a successive intermixture of the colours without their being assimilated or reduced to any uniformity, is certainly beyond all possibility of doubting [...] (Newton 1959-1977, Vol. 1, 182-183-underlining added).

${ }^{17}$ I develop this suggestion in (Walsh in preparation).

18 This phrase comes from Barbara Shapiro (Shapiro 1983, 29). 
Copyright Philosophy of Science 2017

Preprint (not copyedited or formatted)

Please use DOI when citing or quoting

There was a social aspect to this as well: Newton expected that others would draw the same conclusion in the same context. For example, in his correspondence with Lucas (August 1676), Newton wrote:

[Let Lucas examine the experiments given.] For if any of those be demonstrative, they will need no assistants nor leave room for further disputing about what they demonstrate. The main thing he goes about to examin is ye different refrangibility of light. And this I demonstrated by ye Experimentum Crucis. Now if this demonstration be good, there needs no further examination of ye thing; if not good ye fault of it is to be shewn, for ye only way to examin a demonstrated proposition is to examin ye demonstration (Newton 1959-1977, Vol. 2, 79-80).

So, as far as Newton was concerned, the experimentum crucis did not provide 'mere' empirical support; it proved that the "true cause" could be "no other" than the one he had identified (Newton 1959-1977, Vol. 1, 95). And others, having carried out the same experiment, should be compelled to accept the same conclusion.

This social aspect of Newton's epistemology can be found in the Principia. For example, in the scholium to the laws, he writes: "The principles I have set forth are accepted by mathematicians and confirmed by experiments of many kinds" (Newton 1999, 424). And in his manuscript, De gravitatione, Newton writes:

I have undertaken to demonstrate its [i.e. the science of fluid dynamics] individual propositions from abstract principles, sufficiently well known to the student, strictly and geometrically (Newton 2004, 12).

And a few lines later:

The foundations from which this science may be demonstrated are either definitions of certain words, or axioms and postulates no one denies (Newton 2004, 12).

In these passages, Newton tells us that the abstract principles of this science are supposed to be "sufficiently well known to the student" or "definitions of certain words, or axioms and postulates no one denies". The emphasis on students implies undisputed and fundamental principles - i.e. the what a student learns by way of introduction to the field. Newton expressed a similar notion in his Opticks (1704) while introducing the axioms:

For what hath been generally agreed on I content my self to assume under the notion of Principles, in order to what I have farther to write. And this may suffice for an Introduction to Readers of quick Wit and good Understanding not yet versed in Opticks [...] (Newton 1952, 20) 
Copyright Philosophy of Science 2017

Preprint (not copyedited or formatted)

Please use DOI when citing or quoting

There are, then, three components to 'compelled assent': for Newton, some proposition is certain when given (1) the evidence cited, someone of sufficient (2) rationality ('quick wit') and (3) background knowledge ('good understanding) would be forced to accept the truth of that proposition. 
Copyright Philosophy of Science 2017

Preprint (not copyedited or formatted)

Please use DOI when citing or quoting

\section{References}

Achinstein, Peter. 2013. "Evidence and Method: Scientific Strategies of Isaac Newton and James Clerk Maxwell.” In: Oxford Scholarship Online (accessed 16 December 2013).

Ducheyne, Steffen. 2005. “Bacon's Idea and Newton's Practice of Induction.” Philosophica no. 76:115-128.

Ducheyne, Steffen. 2012. The Main Business of Natural Philosophy: Isaac Newton's NaturalPhilosophical Methodology. New York: Springer.

Ducheyne, Steffen. 2013. "The Status of Theory and Hypotheses.” In The Oxford Handbook of British Philosophy in the Seventeenth Century, edited by Peter Anstey, 169-191. Oxford University Press.

Dunlop, Katherine. 2012. "What Geometry Postulates: Newton and Barrow on the relationship of mathematics to nature." In Interpreting Newton, edited by Andrew Janiak and Eric Schliesser, 69-101. Cambridge: Cambridge University Press.

Guicciardini, Niccolò. 2011. Isaac Newton on Mathematical Certainty and Method. Cambridge, Massachusetts: The MIT Press.

Harper, William L. 2011. Isaac Newton's Scientific Method: Turning Data into Evidence about Gravity \& Cosmology. Oxford: Oxford University Press.

Hooke, Robert. 1966/1665. Micrographia: Or, some physiological descriptions of minute bodies made by magnifying glasses, with observations and inquiries thereupon. New York N.Y.: Dover.

Locke, John. 1997/1690. An Essay concerning Human Understanding. Edited by Roger Woolhouse: Penguin Books Limited. Original edition, 1690.

Newton, Isaac. 1672. "A Letter of Mr. Isaac Newton, Professor of the Mathematicks in the University of Cambridge; Containing His New Theory about Light and Colors: Sent by the Author to the Publisher from Cambridge, Febr. 6. 1671/72; In Order to be Communicated to the R. Society “ Philosophical Transactions no. 6 (80):3075-3087.

Newton, Isaac. 1952. Opticks: Or a Treatise of the Reflections, Refractions, Inflections \& Colours of Light: Dover Publications, Inc.

Newton, Isaac. 1959-1977. The Correspondence of Isaac Newton, 7 Volumes. edited by H W Turnbull, J F Scott, A R Hall and Laura Tilling. Cambridge: Published for the Royal Society at the University Press. 
Copyright Philosophy of Science 2017

Preprint (not copyedited or formatted)

Please use DOI when citing or quoting

Newton, Isaac. 1972. Isaac Newton's Philosophiae Naturalis Principia Mathematica, Volume II. edited by Alexandre Koyré and I Bernard Cohen. London: Cambridge University Press.

Newton, Isaac. 1984. The Optical Papers of Isaac Newton: Volume I The Optical Lectures 1670 - 1672. edited by Alan E Shapiro. Cambridge: Cambridge University Press.

Newton, Isaac. 1999. The Principia: Mathematical Principles of Natural Philosophy. edited by I Bernard Cohen and Anne Miller Whitman. Berkeley: University of California Press. Original edition, 1726.

Newton, Isaac. 2004. Isaac Newton: Philosophical Writings. edited by Andrew Janiak. Cambridge: Cambridge University Press.

Shapiro, Alan E. 1989. "Huygens' Traité de la Lumière and Newton's Opticks: Pursuing and Eschewing Hypotheses." Notes and Records of the Royal Society of London no. 43:223247.

Shapiro, Alan E. 1993. Fits, Passions and Paroxysms: Physics, Method and Chemistry and Newton's Theories of Colored Bodies and Fits of Easy Reflection. Cambridge: Cambridge University Press.

Shapiro, Barbara J. 1983. Probability and Certainty in Seventeenth-Century England. Princeton, New Jersey: Princeton University Press.

Smith, George E. 2002. "The Methodology of the Principia." In The Cambridge Companion to Newton, edited by I B Cohen and George E Smith, 138-173. Cambridge: Cambride University Press.

Walsh, Kirsten. 2011. The Aims of Newton's Natural Philosophy. In Early Modern Experimental Philosophy Blog. University of Otago.

Walsh, Kirsten. in preparation. 'Quick wit and good understanding': Newtonian Certainty and 'Compelled Assent'. 